\title{
Outcomes in Patients with PT3NOM0 Breast Cancer with and without Postmastectomy Radiotherapy
}

\author{
Chunyan $\mathrm{Li}^{1,2}$ \\ Jiangfeng Wang ${ }^{1,2}$ \\ Miao $\mathrm{Mo}^{2,3}$ \\ Jing Yuan ${ }^{2,3}$ \\ Jurui Luo ${ }^{1,2}$ \\ Kairui Jin ${ }^{1,2}$ \\ Xuanyi Wang ${ }^{1,2}$ \\ Yilan Yang ${ }^{1,2}$ \\ Jinli $\mathrm{Ma}^{\mathrm{l}, 2}$ \\ Xin $\mathrm{Mei}^{1,2}$ \\ Zhaozhi Yang ${ }^{1,2}$ \\ Xiaoli $\mathrm{Yu}^{\mathrm{l}, 2}$ \\ Xingxing Chen ${ }^{1,2}$ \\ Xiaomao Guo (iD) ${ }^{1,2}$ \\ 'Department of Radiation Oncology, \\ Fudan University Shanghai Cancer \\ Center, Shanghai, 200032, People's \\ Republic of China; ${ }^{2}$ Department of \\ Oncology, Shanghai Medical College, \\ Fudan University, Shanghai, 200032, \\ People's Republic of China; ${ }^{3}$ Department \\ of Cancer Prevention, Fudan University \\ Shanghai Cancer Center, Shanghai, \\ 200032, People's Republic of China
}

Correspondence: Xiaomao Guo; Xingxing Chen

Department of Radiation Oncology,

Fudan University Shanghai Cancer Center,

270 DongAn Road, Shanghai, 200032,

People's Republic of China

Tel +86- I8I21299336

Fax +862I-64031696

Email guoxm1800@I63.com;

xingxing@yahoo.com
Purpose: The role of adjuvant postmastectomy radiotherapy (PMRT) remains controversial for patients with pT3N0M0 breast cancer, especially when patients are treated with the updated adjuvant chemotherapy. Our study aimed to compare locoregional recurrence-free survival (LRFS), disease-free survival (DFS), and breast cancer-specific survival (BCSS) in pT3N0M0 patients with and without postmastectomy radiotherapy.

Patients and Methods: Between October 2000 and 8 September 2016, the database of the Breast Cancer Center of Shanghai yielded 114 patients with node-negative non-metastatic breast cancer larger than $5 \mathrm{~cm}$. Univariate and multivariate analyses were performed to assess the risk factors for survivals. Differences between the two groups were compared using the Log rank test. Results: Fifty-nine (51.8\%) of the patients received adjuvant PMRT. The median follow-up was 62.3 months. Five-year LRFS was $100 \%$ in the PMRT group vs $98.1 \%$ in the non-PMRT group $(\mathrm{P}=0.17)$; 5-year DFS was $97.1 \%$ for the entire cohort, $98.0 \%$ for the PMRT group vs $96.2 \%$ for the non-PMRT group $(\mathrm{P}=0.18)$. Univariate analysis identified that family history of malignant tumors, lymphovascular invasion (LVI), or triple-negative breast cancer (TNBC) molecular subtype were associated with higher locoregional recurrence $(\mathrm{LRR})(\mathrm{P}<0.05)$. No PMRT was the only risk factor independently associated with poorer DFS $(\mathrm{P}=0.048)$ on multivariate analysis. No difference in BCSS was observed between the two groups.

Conclusion: The present study demonstrated a low LRR rate and good survival for nodenegative breast cancer $>5 \mathrm{~cm}$. Patients with family history of malignant tumors, TNBC subtype, LVI positivity, or grade 3 disease are at high risk for LRR and might benefit from PMRT.

Keywords: node-negative, updated systemic treatment, radiotherapy, locoregional recurrence

\section{Plain Language Summary}

It is confusing for both doctors and node-negative non-metastatic breast cancer patients with tumors of $5 \mathrm{~cm}$ or larger to decide whether to receive post-operation radiotherapy. Therefore, we did this research, and our team report that pT3N0M0 breast cancer patients generally had a good prognosis. Patients with high-risk factors such as triple-negative breast cancer subtype, malignant tumor diagnosis among the first- and second-degree relatives, pathological results indicating lymphovascular invasion or high-grade disease should consider postmastectomy radiotherapy (PMRT).

\section{Introduction}

Breast cancer is the most commonly diagnosed malignancy in women and the most commonly diagnosed cancer worldwide. ${ }^{1}$ However, pT3N0M0 breast cancer is rare, 
representing $<1 \%$ of new breast cancer cases. ${ }^{2}$ According to the National Comprehensive Cancer Network (NCCN) guidelines for breast cancer, patients with positive lymph nodes after mastectomy were routinely recommended to undergo radiation therapy, but for those with negative lymph nodes, the indication of PMRT is still controversial, especially for $\mathrm{pT} 3$ disease. $^{3}$

In 2005, the Early Breast Cancer Trialists' Collaborative Group (EBCTCG) demonstrated a reduced 5 -year local recurrence rate (LRR) (6\% to $2 \%)$ for nodenegative patients who underwent PMRT, along with increased non-breast cancer mortality, ${ }^{4}$ while the radiotherapy techniques applied in the EBCTCG analysis were outdated and the database of patients included nodenegative patients with pT1-2 and pT4.

Though without unanimous recommendations, the number of pT3N0M0 patients receiving PMRT is increasing over time, ${ }^{5}$ from $22 \%$ reported between $1998-2002^{5}$ to $42 \%$ between $2000-2010,{ }^{6}$ and the percent is even higher for younger patients $(47 \%$ for those aged $<50$ years from 1998-2007). ${ }^{7}$ Recent studies demonstrated nearly half of patients with pT3N0M0 diagnosis received PMRT., The MD Anderson Cancer Center indicated that $73.5 \%$ of cT3N0 and $64.0 \%$ of pT3N0M0 patients received PMRT. ${ }^{10}$

Considering the cost and side effects of PMRT, it is important to define the role of PMRT for the pT3N0M0 subgroup in this new era of radiotherapy and identify those who can really benefit from PMRT in this setting. Many studies explored the role of PMRT in breast cancer patients with a pathologic diagnosis of pT3N0M0, but the results were conflicting. Hence, we reviewed pT3N0M0 patients in our breast cancer center treated with updated adjuvant chemotherapy. Our study is one of the studies with large sample size regarding pT3N0M0 breast cancer patients, and will help to optimize the treatment strategies for this special group of patients in the new era.

\section{Patients and Methods}

\section{Patients}

From January 2000 to September 2016, 30,099 breast cancer patients were treated in our institute, $253(0.84 \%)$ patients were staged as T3N0M0, a total of 114 female patients with primary breast cancer diagnosed as pT3N0M0 were retrospectively reviewed in our study. All patients were treated with modified mastectomy with or without adjuvant therapy, including chemotherapy, hormonal therapy, and PMRT. Patients with a malignant cancer diagnosis before, or with bilateral breast cancer at diagnosis, or who received neoadjuvant chemotherapy, and those with a follow-up time of less than 4 months were excluded. A positive family history was defined as having malignant tumor among the first- and second-degree relatives. The review of data for this investigation was approved by the Ethic Committee Office of Fudan University Shanghai Cancer Center.

\section{Treatments}

Among patients who underwent PMRT, 4 patients received two-dimensional radiotherapy (2DRT), 27 patients received three-dimensional conformal radiotherapy (3DCRT), 22 patients received intensity modulated radiotherapy (IMRT), 6 patients received PMRT but without radiation technique information. When PMRT was used, a dose of 50 Gy in 25 fractions was delivered to the chest wall without regional nodal basins.

\section{Statistical Analysis}

Locoregional recurrence (LRR) was defined as disease recurrence in the ipsilateral chest wall or the ipsilateral regional lymph nodal basins (axilla, internal mammary lymph node, supraclavicular fossa, or infraclavicular fossa). Distant metastasis (DM) was defined as disease recurrence other than at LRR sites. Disease-free survival (DFS) was defined as living without any LRR or DM events. Time to locoregional free survival (LRFS), DFS, and breast cancer-specific survival (BCSS) were calculated from the date of pathology diagnosis. The clinicopathological characteristics between two groups were compared using Pearson's Chi-square test or Fisher exact test. Cox proportional hazards models are used to identify prognostic factors of LRFS and DFS. Variables with a P-value less than 0.2 in univariate analysis and those reported as important in previous studies were included in multivariate analysis. Survivals were calculated by the Kaplan-Meier method and comparisons were performed using the Log rank test. Because there was a low rate of LRR (2/114, $1.75 \%$ ), multivariate analysis was not performed for LRFS. The distribution of factors between groups was analyzed using the chi-squared method. P-values of less than 0.05 were considered statistically significant. Statistical analyses were performed using $\mathrm{R}$ package 3.6.2 (https://cran.r-project.org/). 


\section{Results}

\section{Patient and Tumor Characteristics}

The median follow-up time of patients was 62.3 (range, 4.6-211.7) months for the entire cohort, 61.9 months for the PMRT cohort, and 62.7 months for the non-PMRT cohort. Totally, $80.7 \%$ of patients received adjuvant chemotherapy. The majority $(73 / 92,79.35 \%)$ of the patients received anthracycline-based chemotherapy, with approximately half $(47 / 92,51.1 \%)$ of the patients receiving a combination of anthracycline and taxane, while $13 \%$ $(12 / 92)$ of the patients received taxane-based chemotherapy only. A small group $(7 / 92,7.61 \%)$ of patients received chemotherapies other than those mentioned above, with five of seven undergoing CMF (cyclophosphamide, methotrexate, 5-fluorouracil) treatment. Complete axillary lymph node dissection was performed in 95 (83.3\%) patients, while sentinel lymph node biopsy was performed in $19(16.7 \%)$ patients. The median number of lymph nodes dissected during surgery was 15 . In total, $85.0 \%$ (51/60) of ER/PR positive patients received hormonal therapy with either tamoxifen or an aromatase inhibitor, while $56.8 \%$ (21/37) of patients who were HER2-positive were treated with trastuzumab. Clinical and pathological characteristics of the patients are listed in Table 1.

Of the 114 patients enrolled in the study, fifty-nine (59/ 114, 51.8\%) patients received PMRT, while 55 (55/114, $48.2 \%)$ did not. One patient in the PMRT group had positive margins. Younger patients were more likely to be offered radiation $(\mathrm{P}=0.002)$, while other variables were balanced between the two groups. Approximately $61.2 \%$ of premenopausal patients received PMRT $(\mathrm{P}=0.079)$, and more patients in the PMRT group had lymphovascular invasion (LVI) $(27.1 \%$ vs $12.73 \%$, $\mathrm{P}=0.210)$ or received adjuvant chemotherapy $(84.7 \%$ vs $76.4 \%, \mathrm{P}=0.071$ ) compared with the non-PMRT group. The use of PMRT across different years showed a relatively stable trend after 2010 , about $50 \%$ of pT3N0M0 patients underwent PMRT.

\section{LRR According to PMRT Use}

The 5-year cumulative LRFS was $98.1 \%$ in the non-PMRT cohort and $100 \%$ in the PMRT cohort. The cumulative survival of LRFS is plotted in Figure 1 according to PMRT use. PMRT tended to improve LRFS for pT3N0M0 patients but did not reach statistical significance $(\mathrm{P}=0.17)$. Two LRR events occurred, both of which were in the non-PMRT cohort. Both events occurred in patients with triple-negative breast cancer (TNBC) molecular subtype, grade 3 pathologic features, and LVI positivity. One of the patients experienced relapse in the regional axillary lymph nodes 10 months after mastectomy, without simultaneous distant failure. This patient had a total of 10 lymph nodes removed at axillary dissection and had a relatively bigger tumor of $12 \mathrm{~cm}$ in diameter and received taxanebased chemotherapy without PMRT. The second patient had LRR in the chest wall and subclavicular lymph nodes with simultaneous distant failure in bone, pleura, and mediastinal lymph nodes 8 years after primary surgery. This patient had 20 lymph nodes removed at axillary dissection and received adjuvant chemotherapy without PMRT. Both patients were alive at the last follow-up. No LRR event was observed after distant metastasis. We did not identify any events in the only patient in the PMRT group that had positive margins.

We performed a univariate analysis on LRFS (Table 2). Patients with a family history of malignant tumors had a poorer LRFS $(\mathrm{P}=0.0078)$. TNBC patients were at risk of higher LRR than non-TNBC patients, regardless of whether we defined HER2 ++ (immunohistochemical staining) as negative $(\mathrm{P}=0.0062)$ or positive $(\mathrm{P}=0.0014)$. Furthermore, if we divided patients into three subtypes, patients with luminal or HER2-positive subtypes had better LRFS than TNBC patients $(\mathrm{P}=0.023$ and $\mathrm{P}=0.035$; respectively). ER positivity seemed to be a protective factor for LRFS in pT3N0M0 patients $(\mathrm{P}=0.059)$. The univariate analysis showed grade 3 histologic features $(\mathrm{P}=0.078)$ and LVI positivity $(\mathrm{P}=0.0039)$ were unfavorable prognostic factors for LRFS. Because of the rarity of LRR events, multivariate analysis was not performed for LRFS.

\section{DFS According to PMRT Use}

Five-year DFS was $96.2 \%$ in the non-PMRT cohort, and $98.0 \%$ in the PMRT cohort $(\mathrm{P}=0.18)$. Among the 5 patients who had events during follow-up, two patients had LRR, and four patients developed distant metastasis (three in the non-PMRT group and one in the PMRT group). The only distant metastasis in PMRT group occurred in bone at 40.7 months after primary surgery and this patient was 30 years old at diagnosis with luminal subtype, had a total of 22 lymph nodes removed at axillary dissection, and finally died of breast cancer 2 years later. She received hormonal therapy and adjuvant chemotherapy based on anthracycline and taxane. Among the three patients with distant metastasis in the non-PMRT cohort, one had simultaneous LRR and has 
Table I Patients' Characteristics

\begin{tabular}{|c|c|c|c|c|c|c|c|}
\hline \multirow[t]{2}{*}{ Characteristics } & \multicolumn{2}{|c|}{ All Patients $(n=1 \mid 4)$} & \multicolumn{2}{|c|}{ PMRT (n = 59) } & \multicolumn{2}{|c|}{ No PMRT $(n=55)$} & \multirow[t]{2}{*}{$P$ value } \\
\hline & No. & $\%$ & No. & $\%$ & No. & $\%$ & \\
\hline \multicolumn{8}{|l|}{ Age (years) } \\
\hline Median (range) & $53(26-80)$ & & $50(26-80)$ & & $57(28-78)$ & & \\
\hline$<50$ & $4 I$ & 35.96 & 29 & 49.2 & 12 & 21.8 & 0.002 \\
\hline$\geq 50$ & 73 & 64.04 & 30 & 50.8 & 43 & 78.2 & \\
\hline \multicolumn{8}{|l|}{ Family history } \\
\hline Negative & 99 & 86.8 & 51 & 86.4 & 48 & 87.3 & 0.896 \\
\hline Positive & 15 & 13.16 & 8 & 13.6 & 7 & 12.7 & \\
\hline \multicolumn{8}{|l|}{ Menstrual status } \\
\hline Premenopausal & 49 & 42.98 & 30 & 50.8 & 19 & 34.5 & 0.079 \\
\hline Postmenopausal & 65 & 57.02 & 29 & 49.2 & 36 & 65.5 & \\
\hline \multicolumn{8}{|l|}{ Pathology } \\
\hline IDC & 94 & 82.46 & 52 & 88.1 & 42 & 76.4 & 0.099 \\
\hline Other & 20 & 17.54 & 7 & 11.9 & 13 & 23.6 & \\
\hline \multicolumn{8}{|l|}{ Tumor size (cm) } \\
\hline Median (range) & $6.0(5.1-16.0)$ & & $6.0(5.1-12.0)$ & & $6.0(5.1-16.0)$ & & 0.383 \\
\hline $5.1-7.0$ & 43 & 37.72 & 20 & 33.9 & 23 & 41.8 & \\
\hline$>7.0$ & 71 & 62.28 & 39 & 66.1 & 32 & 58.2 & \\
\hline \multicolumn{8}{|l|}{ Grade } \\
\hline $1-I I$ & 58 & 50.88 & 32 & 54.24 & 26 & 47.27 & 0.968 \\
\hline III & 42 & 36.84 & 23 & 38.98 & 19 & 34.55 & \\
\hline Unknown & 14 & 12.28 & 4 & 6.78 & 10 & 18.18 & \\
\hline \multicolumn{8}{|l|}{ ALND } \\
\hline$\leq 15$ & 58 & 50.9 & 27 & 45.8 & 31 & 56.4 & 0.258 \\
\hline$>15$ & 56 & 49.1 & 32 & 54.2 & 24 & 43.6 & \\
\hline \multicolumn{8}{|l|}{ ER } \\
\hline Negative & 46 & 40.4 & 22 & 37.3 & 24 & 43.6 & 0.432 \\
\hline Positive & 65 & 57.0 & 36 & 61.0 & 29 & 52.7 & \\
\hline Unknown & 3 & 2.63 & 1 & 1.69 & 2 & 3.64 & \\
\hline \multicolumn{8}{|l|}{ PR } \\
\hline Negative & 59 & 51.8 & 31 & 52.5 & 28 & 50.9 & 0.948 \\
\hline Positive & 52 & 45.6 & 27 & 45.8 & 25 & 45.5 & \\
\hline Unknown & 3 & 2.63 & 1 & 1.69 & 2 & 3.64 & \\
\hline \multicolumn{8}{|l|}{ HER2 } \\
\hline Negative & 70 & 61.4 & 37 & 62.7 & 33 & 60.0 & 0.882 \\
\hline Positive & 37 & 32.5 & 19 & 32.2 & 18 & 32.7 & \\
\hline Unknown & 7 & 6.14 & 3 & 5.08 & 4 & 7.27 & \\
\hline \multicolumn{8}{|l|}{ Ki-67 } \\
\hline$\leq 15 \%$ & 30 & 26.32 & 18 & 30.5 & 12 & 21.8 & 0.798 \\
\hline$>15 \%$ & 56 & 49.12 & 32 & 54.2 & 24 & 43.6 & \\
\hline Unknown & 28 & 24.56 & 9 & 15.3 & 19 & 34.5 & \\
\hline \multicolumn{8}{|l|}{ Subtype } \\
\hline Non-TNBC & 90 & 78.95 & 47 & 79.7 & 43 & 78.2 & 0.990 \\
\hline TNBC & 21 & 18.42 & II & 18.6 & 10 & 18.2 & \\
\hline Unknown & 3 & 2.63 & 1 & 1.7 & 2 & 3.6 & \\
\hline
\end{tabular}

(Continued) 
Table I (Continued).

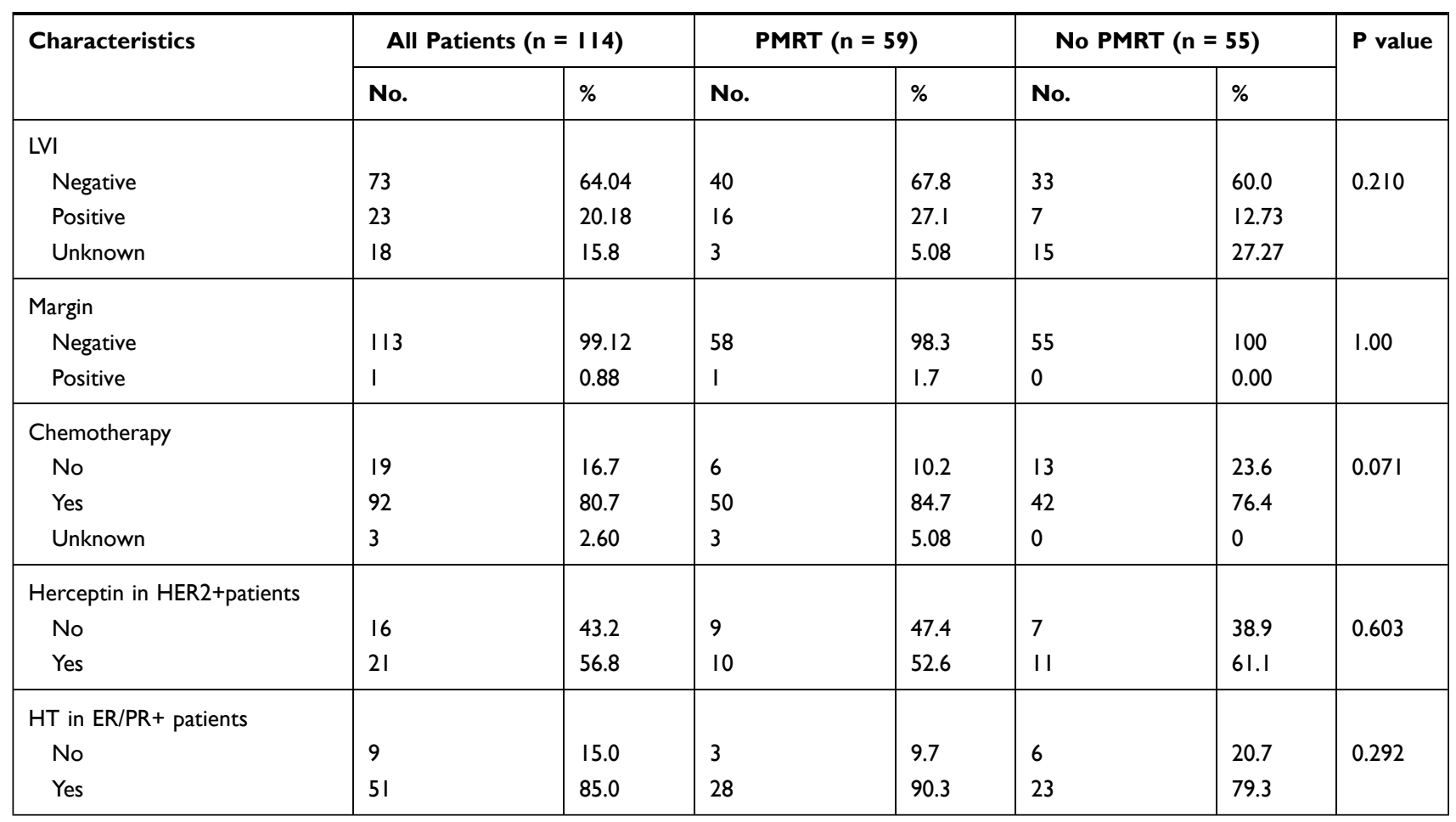

Abbreviations: PMRT, post-mastectomy radiotherapy; IDC, invasive ductal carcinoma; ALND, axillary lymph node dissection; ER, estrogen receptor; PR, progesterone receptor; HER2, human epithelial growth factor receptor-2; TNBC, triple-negative breast cancer; LVI, lymphovascular invasion; HT, hormonal therapy.

been described before, and the other two patients both suffered lung metastasis, with one having mediastinal lymph node involvement. A total of 17 and 18 lymph nodes were removed at axillary dissection in the two patients with lung metastasis. The patient who developed DM 12.1 months after primary surgery died of breast cancer approximately 2 years later, while the other patient who developed DM 8.3 years after primary surgery was still alive at last follow-up. Both patients received hormonal therapy and adjuvant chemotherapy based on anthracycline and taxane. The former had grade 3 histological features and was HER2-positive, undergoing two cycles of trastuzumab treatment.

We performed univariate $(\mathrm{P}=0.18$; Figure $2 \mathrm{~A})$ and multivariate $(\mathrm{P}=0.048$; Figure $2 \mathrm{~B})$ analysis of DFS with factors reported to be important in the clinical setting (Table 3), and identified PMRT as the only independent favorable factor in DFS.

\section{Cumulative Survival of BCSS}

Five-year BCSS was $97.9 \%$ in the non-PMRT group and $96.3 \%$ in the PMRT cohort. The BCSS curves for the PMRT and non-PMRT cohorts overlapped with each other, with no differences observed $(\mathrm{P}=0.92)$.

\section{Discussion}

The application of PMRT in patients with pT3N0M0 breast cancer remains controversial. Floyd et $\mathrm{al}^{11}$ assessed the value of PMRT in patients with node-negative breast tumors of $5 \mathrm{~cm}$ or larger. They found a low 5-year LRR rate of 7.6\% (95\% confidence interval, 3-16\%) and 5-year DFS of $86 \%$ in the cohort and demonstrated LVI as a risk factor for worse LRFS, DFS, and OS. Taghian et $\mathrm{al}^{12}$ reviewed patients with tumors larger than $5 \mathrm{~cm}$ who were treated in five NSABP node-negative trials, and identified locoregional recurrence in $7.2 \%$ of patients with tumors of more than $5 \mathrm{~cm}$. In our study, the 5 -year LRR rate was only $1.9 \%$ and 5 -year DFS was $90.5 \%$ in the non-PMRT group, better than the findings in prior studies. Moreover, the risk of LRR at 5 years in patients treated with PMRT was even lower at $0 \%$. We noticed that the two abovementioned studies included patients between 1981 and 2002 while ours included patients between 2000 and 2016 when more advanced adjuvant chemotherapies were applied, it is likely that the improvements in systematic treatment and radiation techniques could have contributed to the lower rate of LRR and better DFS in our study.

Jagsi et $\mathrm{al}^{13}$ analyzed the local recurrence in 877 nodenegative patients treated by mastectomy without PMRT. 

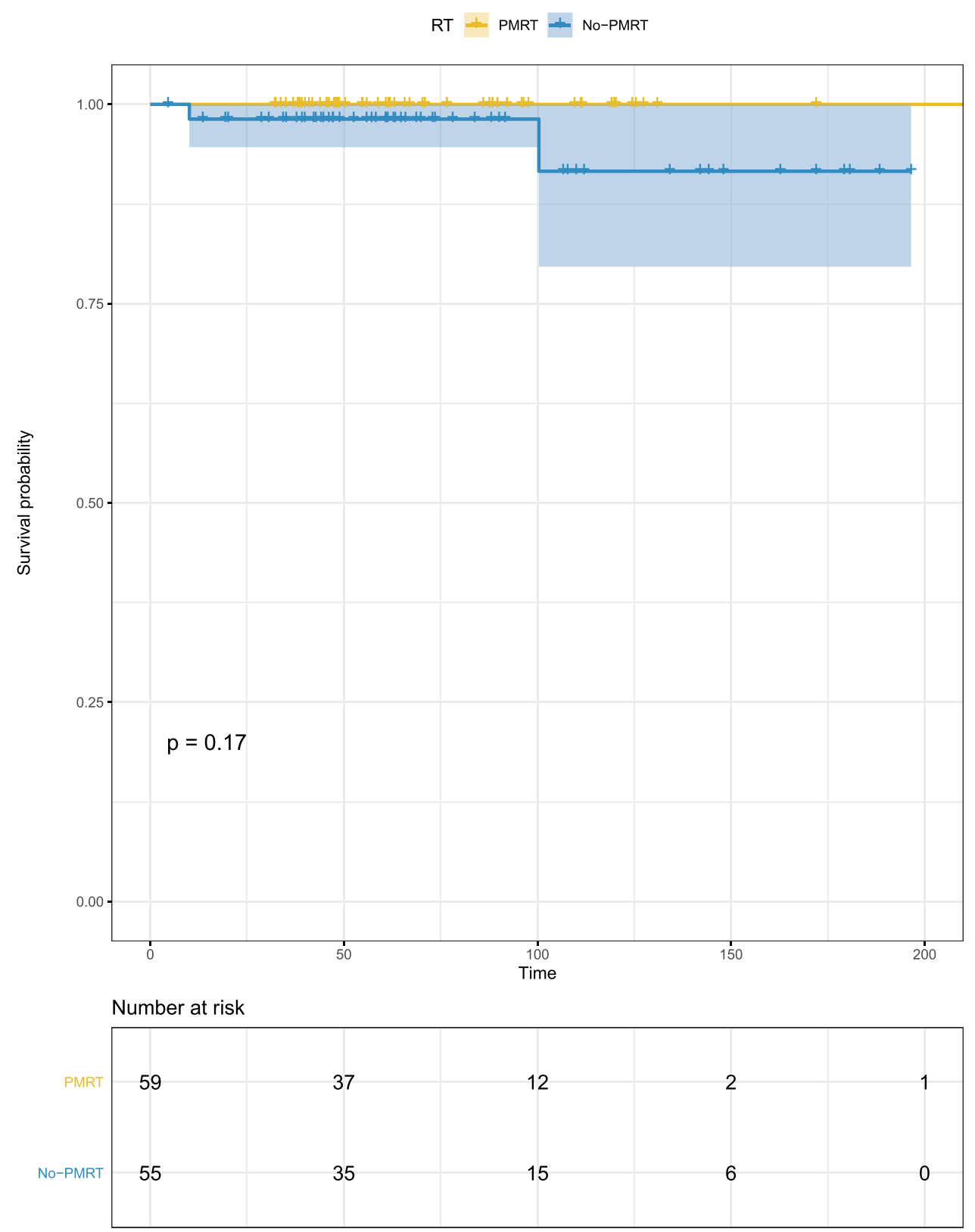

Figure I LRFS of patients with PT3NOMO breast cancer according to PMRT.

They found the chest wall was the most common site of failure, and tumor size greater than $2 \mathrm{~cm}$, margin less than $2 \mathrm{~mm}$, premenopausal status, and LVI were significant prognostic factors. In 2019, an analysis of the survival of 14464 female patients with TNBC diagnosed with pT14N0M0 from the NCDB (2004-2014) was reported, they found PMRT was associated with better OS for TNBC patients with pT3 disease. $^{8}$ We only included patients with tumors of more than $5 \mathrm{~cm}$, consistent with the results of Floyd et al and Jagsi et al, LVI was also identified as an unfavorable factor, and, with more specific information, we also identified TNBC and a family history of malignant tumors as unfavorable prognostic factors. Two of three patients who had all the three risk factors (TNBC subtype, grade 3, LVI +) developed LRR in our study. Taken together, we agree with the conclusions of Jagsi et al that node-negative patients with high-risk factors should be recommended PMRT to improve locoregional control.

In 2017, a retrospective, multi-institutional review regarding PMRT for pT3N0M0 patients was reported with a median follow-up of 6.2 years and 5.3 years in the non-PMRT and PMRT cohorts, respectively. ${ }^{14}$ In this 
Table 2 Local-Recurrence Rate and Univariate Analysis of LRFS

\begin{tabular}{|c|c|c|}
\hline Variables & $\begin{array}{l}\text { LRR \% (Events/No. of } \\
\text { Patients) }\end{array}$ & $P$ value \\
\hline $\begin{array}{l}\text { Family history } \\
\text { Negative } \\
\text { Positive }\end{array}$ & $\begin{array}{l}1.01(1 / 99) \\
6.67(1 / 15)\end{array}$ & 0.0078 \\
\hline $\begin{array}{l}\text { ER status } \\
\text { Negative } \\
\text { Positive }\end{array}$ & $\begin{array}{l}4.35(2 / 46) \\
0.00(0 / 65)\end{array}$ & 0.0593 \\
\hline $\begin{array}{l}\text { Subtype } \\
\qquad \text { TNBC } \\
\text { Non-TNBC }\end{array}$ & $\begin{array}{l}9.52(2 / 21) \\
0.00(0 / 90)\end{array}$ & 0.0062 \\
\hline $\begin{array}{l}\text { Subtype (HER2++ as } \\
\text { positive) } \\
\text { TNBC } \\
\text { Non-TNBC }\end{array}$ & $\begin{array}{l}10.5(2 / 19) \\
0.00(0 / 92)\end{array}$ & 0.0014 \\
\hline $\begin{array}{l}\text { Subtype } \\
\text { TNBC } \\
\text { HER2+ } \\
\text { Luminal }\end{array}$ & $\begin{array}{l}9.52(2 / 21) \\
0.00(0 / 24) \\
0.00(0 / 66)\end{array}$ & 0.0235 \\
\hline $\begin{array}{r}\text { PMRT } \\
\text { No } \\
\text { Yes }\end{array}$ & $\begin{array}{l}3.64(2 / 55) \\
0.00(0 / 59)\end{array}$ & 0.1701 \\
\hline $\begin{array}{c}\text { Grade } \\
\text { I-II } \\
\text { III }\end{array}$ & $\begin{array}{l}0.00(0 / 58) \\
4.76(2 / 42)\end{array}$ & 0.0776 \\
\hline $\begin{array}{l}\text { LVI } \\
\text { Negative } \\
\text { Positive }\end{array}$ & $\begin{array}{l}0.00(0 / 73) \\
8.70(2 / 23)\end{array}$ & 0.0039 \\
\hline
\end{tabular}

Abbreviations: LRR, local-recurrence rate; ER, estrogen receptor; TNBC, triplenegative breast cancer; HER2, human epithelial growth factor receptor-2; PMRT, post-mastectomy radiotherapy; LVI, lymphovascular invasion.

study, there was an isolated local regional recurrence rate of $12 \%$ at 10 years without PMRT, and 5- and 10-year LRFS for the PMRT and non-PMRT cohorts were 98\% and $88 \%$, respectively $(\mathrm{P}=0.15) .{ }^{14}$ Consistent with their outcome, PMRT was also found to be associated with better locoregional control, but without statistical significance in our study $(\mathrm{P}=0.17)$, which might be attributed to the number of patients, and, more importantly, the number of events were relatively small in our study. In a study by Goulart et al ${ }^{15}$ that included 100 patients with $\mathrm{pT} 2=5.0 \mathrm{~cm}$ and pT3 $>5.0 \mathrm{~cm}$ tumors treated by mastectomy, a low LRR rate $(2.3 \%$ in the PMRT group vs $8.9 \%$ in the nonPMRT group) was demonstrated, but, similar to our results, they found no significant improvement in LRFS and BCSS with PMRT, and concluded that PMRT should be considered for patients with grade 3 histologic features and patients without hormonal therapy. In our study, there was also a trend toward worse LRFS for patients with ER negativity and grade 3 histologic features. Besides, in our study, seven of 28 patients (25\%) treated before 2008 received adjuvant chemotherapy, while 44 of $86(81.9 \%)$ patients treated after 2008 received adjuvant chemotherapy. Anthracycline-based adjuvant chemotherapy was delivered to $57.1 \%$ of patients before 2008 , while anthracycline- and taxane-based adjuvant chemotherapy took the dominant place (52.3\%) after 2008. Moreover, the application of trastuzumab in HER2-positive patients increased from $0 \%$ before 2008 to $56.8 \%$ after 2008 , and hormonal therapy in ER-/PR-positive patients increased from $50 \%$ before 2008 to $93.8 \%$ after 2008. For patients in PMRT group were mainly from 2009 to 2016, when systematic treatments were improved, this might partly explain why PMRT increased LRFS but without statistical significance.

Studies of pT3N0M0 patients in large populations at individual or multiple institutions have been lacking because of the infrequency of this clinical scenario, and thus many databases have been explored to analyze the features of this rare cohort. A study by Johnson et $\mathrm{al}^{6}$ analyzed 2525 patients treated between 2000 and 2010 from the SEER database and found a benefit for PMRT. Multivariate analysis indicated that PMRT improved OS (HR 0.63, $\mathrm{P}<0.001$ ) and cancer-specific survival (HR 0.77, $\mathrm{P}=0.045$ ), and concluded that PMRT should be strongly considered in T3N0M0 patients. Cassidy et al ${ }^{16}$ analyzed data from National Cancer Data Base (NCDB) including 3437 patients with pT3N0M0 breast cancer who were initially treated by mastectomy between 2003 and 2011 . They concluded that PMRT was found to be associated with improved OS ( $86.3 \%$ vs $66.4 \%, \mathrm{P}<0.01)$, regardless of surgical margin status, tumor size, and receipt of systemic therapy. Francis et $\mathrm{al}^{9}$ analyzed the survival of 4291 pT3N0M0 patients from the NCDB and found improved OS for patients with PMRT on multivariate analysis (HR $0.72, \mathrm{P}<0.001)$ and in the propensity score matching cohort $(\mathrm{P}<0.001)$. However, both the SEER database and NCDB had no records of LRR or detailed information regarding chemotherapy and hormonal therapy, NCDB even had no information on the cause of death, which might indicate that death from causes other than breast cancer may have influenced the analyses of OS, as PMRT group had more younger patients in their studies. On the other hand, the large database studies cited may not be informative on the impact of RT on distant relapse or 
A

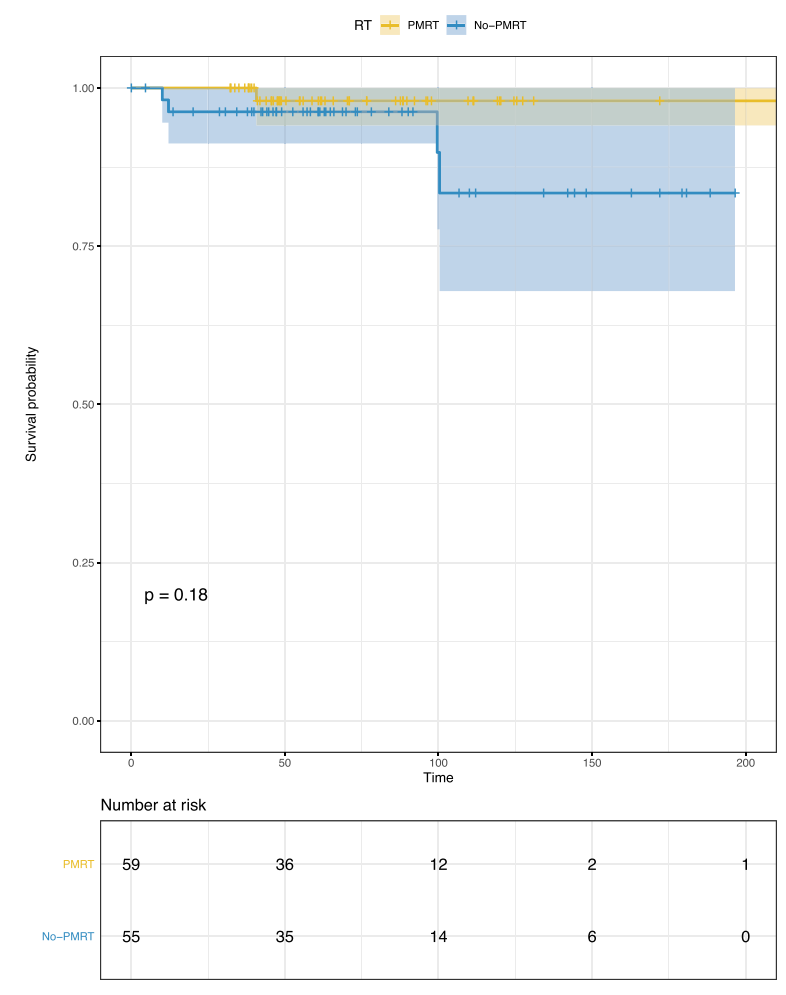

B

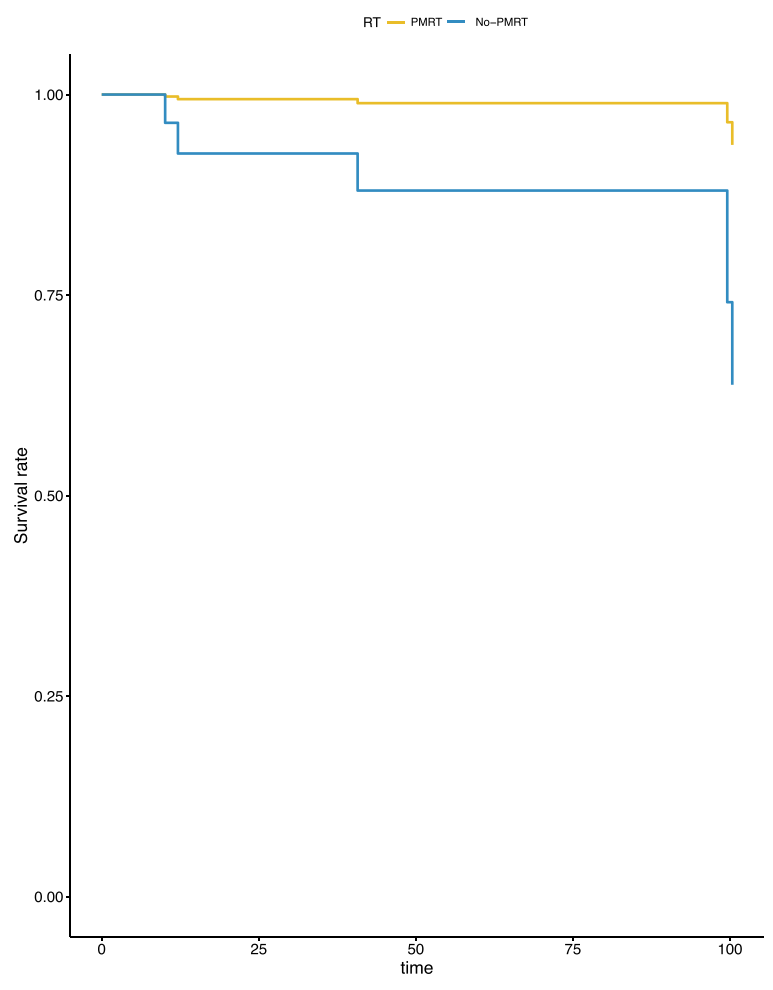

Figure 2 DFS according to PMRT use. (A) DFS from univariate analysis. (B) Co-adjusted curves of DFS from multivariate analysis.

mortality without the knowledge of LRR. Another analysis of pT3NOM0 patients from the SEER database including patients less than 50 years old found no differences in BCSS and OS. ${ }^{7}$ In our study, we did not find a significant difference in BCSS between the two groups. Altogether, we found that there was a favorable survival for pT3N0M0 breast cancer patients, especially for those who received PMRT.

It is interesting that PMRT is the only independent factor favorable for DFS yet not so for other outcomes in our study. We think variable treatment methods patients may get when they developed local-regional recurrence (LRR) or distant metastasis might have contributed to the result that no difference of BCSS was seen between the two groups. Second, the follow-up time may be also not long enough to get a conclusion on BCSS. As for LRFS, there were only 2 patients developed LRR in our cohort, which may be the reason why no benefit of PMRT on LRFS was seen between the two groups. Besides, it is also possible that selection bias might have contributed to the results. Bigger sample size and longer follow-up are needed to get a solid conclusion.

Another intriguing thing is that a hypothesis has been proposed indicating that patients with breast cancer with a larger tumor size $(>5 \mathrm{~cm})$ may represent a rare subgroup with benign biological behaviors. ${ }^{17}$ In particular, a low LRR incidence was reported in previous studies, supporting the hypothesis indirectly. With the development of breast cancer classification by genotype and immunophenotype, the diagnosis for this rare cohort with pT3N0M0 breast cancer may be better interpreted. Patients who are at high risk may be distinguished from those who are not, thus avoiding unnecessary expenditure and toxicities from various treatments.

The main strength of our study is that it represents a relatively contemporary cohort of patients treated with updated systemic therapies. We were also able to obtain relatively specific clinical and pathologic information of patients. Conversely, one limitation is that, like all retrospective studies, it has selection bias and some missing information.

\section{Conclusion}

Altogether, the results of our present study confirmed a favorable survival for pT3N0M0 patients except for those with high-risk factors. With contemporary systemic therapies, the 5-year LRR rate was low in patients treated with $(0 \%)$ or without PMRT (1.9\%). Selected pT3N0M0 breast cancer patients with high-risk factors, such as 
Table 3 Univariate and Multivariate Analysis of DFS

\begin{tabular}{|c|c|c|c|c|}
\hline \multirow[t]{2}{*}{ Variables } & \multirow{2}{*}{$\begin{array}{l}\text { Disease Progression\% } \\
\text { (Events/No. of Patients) }\end{array}$} & \multirow{2}{*}{$\begin{array}{l}\text { Univariate Analysis } \\
P \text { value }\end{array}$} & \multicolumn{2}{|c|}{ Multivariate Analysis } \\
\hline & & & $P$ value & HR \\
\hline $\begin{array}{l}\text { Family history } \\
\text { Negative } \\
\text { Positive }\end{array}$ & $\begin{array}{l}9.09(9 / 99) \\
20.0(3 / 15)\end{array}$ & 0.024 & 0.2533 & 7.57403 \\
\hline $\begin{array}{l}\text { Menstrual status } \\
\text { Premenopausal } \\
\text { Postmenopausal }\end{array}$ & $\begin{array}{l}8.16(4 / 49) \\
12.3(8 / 65)\end{array}$ & 0.61 & 0.6351 & 2.32795 \\
\hline $\begin{array}{l}\text { Age } \\
\qquad \begin{array}{l}\geq 50 \\
<50\end{array}\end{array}$ & $\begin{array}{l}\text { II.0(8/73) } \\
9.76(4 / 41)\end{array}$ & 1.0 & 0.9111 & 1.18348 \\
\hline $\begin{array}{l}\text { Tumor size }(\mathrm{cm}) \\
\begin{array}{l}5.1-7 \\
>7\end{array}\end{array}$ & $\begin{array}{l}5 / 43(11.6) \\
7 / 7 \mid(9.86)\end{array}$ & 0.57 & 0.1780 & 8.66409 \\
\hline $\begin{array}{c}\text { Grade } \\
\text { I-II } \\
\text { III }\end{array}$ & $\begin{array}{l}8 / 58(13.8) \\
3 / 42(7.14)\end{array}$ & 0.42 & 0.3561 & 0.26012 \\
\hline $\begin{array}{l}\text { LVI } \\
\text { Negative } \\
\text { Positive }\end{array}$ & $\begin{array}{l}7 / 73(9.59) \\
2 / 23(8.70)\end{array}$ & 0.97 & 0.9332 & 0.90240 \\
\hline $\begin{array}{r}\text { ALND } \\
>15 \\
\leq 15\end{array}$ & $\begin{array}{l}7 / 56(12.5) \\
5 / 58(8.62)\end{array}$ & 0.35 & 0.1834 & 0.15988 \\
\hline $\begin{array}{l}\text { Subtype } \\
\text { TNBC } \\
\text { Non-TNBC }\end{array}$ & $\begin{array}{l}2 / 19(10.5) \\
9 / 92(9.78)\end{array}$ & 0.8 & 0.1405 & 29.82472 \\
\hline $\begin{array}{l}\text { ER status } \\
\text { Positive } \\
\text { Negative }\end{array}$ & $\begin{array}{l}6 / 65(9.23) \\
5 / 46(10.9)\end{array}$ & 0.6 & 0.4286 & 12.44894 \\
\hline $\begin{array}{l}\text { PR status } \\
\text { Positive } \\
\text { Negative }\end{array}$ & $\begin{array}{l}4 / 52(7.69) \\
7 / 59(11.9)\end{array}$ & 0.27 & 0.3125 & 0.03505 \\
\hline $\begin{array}{l}\text { HER2 status } \\
\text { Negative } \\
\text { Positive }\end{array}$ & $\begin{array}{l}8 / 74(10.8) \\
3 / 37(8.10)\end{array}$ & 0.75 & 0.4763 & 3.46134 \\
\hline $\begin{array}{l}\text { PMRT } \\
\text { No } \\
\text { Yes }\end{array}$ & $\begin{array}{l}4 / 59(6.78) \\
8 / 55(14.5)\end{array}$ & 0.38 & 0.0485 & $|5.7780|$ \\
\hline
\end{tabular}

Abbreviations: LRR, local-recurrence rate; HR, hazard ratio; LVI, lymphovascular invasion; ALND, axillary lymph node dissection; TNBC, triple-negative breast cancer; ER, estrogen receptor; PR, progesterone receptor; HER2, human epithelial growth factor receptor-2; PMRT, post-mastectomy radiotherapy.

TNBC subtype, grade 3 histologic features, and LVI+ may benefit from PMRT. On the other hand, limited by the sample size, patient selection bias might also be one of the interpretations for the better DFS in our study and the OS difference seen in the studies from the SEER and NCDB databases. So, studies stratified by genotype or 
immunotype as well as larger studies are warranted to better understand the biological characteristics and survival differences of this rare cohort. Individualization of radiation therapy may be indicated based on the different biological parameters.

\section{Abbreviations}

ALND, axillary lymph node dissection; BCSS, breast cancerspecific survival; DFS, disease-free survival; DM, distant metastasis; EBCTCG, Early Breast Cancer Trialists' Collaborative Group; ER, estrogen receptor; HER2, human epithelial growth factor receptor-2; HT, hormonal therapy; IDC, invasive ductal carcinoma; LRFS, locoregional recurrence-free survival; LRR, locoregional recurrence; LVI, lymphovascular invasion; NCCN, National Comprehensive Cancer Network; OS, overall survival; PMRT, postmastectomy radiotherapy; PR, progesterone receptor; SEER, Surveillance, Epidemiology, and End Results; TNBC, triplenegative breast cancer.

\section{Data Sharing Statement}

The data that support the findings of this study are available from the patient records of the Fudan University Shanghai Cancer Center, Shanghai, China; but restrictions apply to the availability of these data, which were used under license for the current study, and so are not publicly available. Data are however available from the authors upon reasonable request and with permission of the Fudan University Shanghai Cancer Center, Shanghai, China.

\section{Ethics Approval and Informed Consent}

Ethics approval for this study was obtained from the Ethic Committee Office of Fudan University Shanghai Cancer center, the reference numbers are 1807188-4. The database complies with relevant data protection and privacy regulations, and that this study was conducted in accordance with the Declaration of Helsinki.

\section{Consent for Publication}

This manuscript is approved by all authors for publication. The work described was original research that has not been published previously, and not under consideration for publication elsewhere, in whole or in part. All the authors listed have approved the manuscript that is enclosed.

\section{Acknowledgments}

We thank H. Nikki March, PhD, from Liwen Bianji, Edanz Editing China (www.liwenbianji.cn/ac), for editing the English text of a draft of this manuscript.

\section{Author Contributions}

All authors made a significant contribution to the work reported, whether that is in the conception, study design, execution, acquisition of data, analysis and interpretation, or in all these areas; took part in drafting, revising or critically reviewing the article; gave final approval of the version to be published; have agreed on the journal to which the article has been submitted; and agree to be accountable for all aspects of the work.

\section{Funding}

The collection, analysis, and interpretation of the data in this paper were supported by the National Natural Science Foundation of China (grant number 8197110875, 81602668), the Shanghai Youth Medical TalentsSpecialist Program.

\section{Disclosure}

The authors report no conflicts of interest in this work.

\section{References}

1. Sung H, Ferlay J, Siegel RL, et al. Global cancer statistics 2020: GLOBOCAN estimates of incidence and mortality worldwide for 36 cancers in 185 countries. CA Cancer J Clin. 2021. doi:10.3322/ caac. 21660

2. Helinto M, Blomqvist C, Heikkila P, Joensuu H. Post-mastectomy radiotherapy in pT3N0M0 breast cancer: is it needed? Radiother Oncol. 1999;52(3):213-217. doi:10.1016/S0167-8140(99)00099-7

3. National Comprehensive Cancer Network. Breast cancer version 4.; 2020. Available from: https://www.nccn.org/. Accessed April 4, 2020.

4. Clarke M, Collins R, Darby S, et al. Effects of radiotherapy and of differences in the extent of surgery for early breast cancer on local recurrence and 15-year survival: an overview of the randomised trials. Lancet. 2005;366(9503):2087-2106.

5. McCammon R, Finlayson C, Schwer A, Rabinovitch R. Impact of postmastectomy radiotherapy in $\mathrm{T} 3 \mathrm{~N} 0$ invasive carcinoma of the breast: a surveillance, epidemiology, and end results database analysis. Cancer. 2008;113(4):683-689. doi:10.1002/cncr.23611

6. Johnson ME, Handorf EA, Martin JM, Hayes SB. Postmastectomy radiation therapy for T3N0: a SEER analysis. Cancer. 2014;120 (22):3569-3574. doi:10.1002/cncr.28865

7. Yan W, Christos P, Nori D, Chao KS, Ravi A. Is there a cause-specific survival benefit of postmastectomy radiation therapy in women younger than age 50 with T3N0 invasive breast cancer? A SEER database analysis: outcomes by receptor status/race/age: analysis using the NCI surveillance, epidemiology, and end results (SEER) database. Am J Clin Oncol. 2013;36(6):552-557. doi:10.1097/ COC.0b013e31825d529b 
8. Haque W, Verma V, Farach A, Brian Butler E, Teh BS. Postmastectomy radiation therapy for triple negative, node-negative breast cancer. Radiother Oncol. 2019;132:48-54. doi:10.1016/j. radonc.2018.11.012

9. Francis SR, Frandsen J, Kokeny KE, Gaffney DK, Poppe MM. Outcomes and utilization of postmastectomy radiotherapy for T3N0 breast cancers. Breast. 2017;32:156-161. doi:10.1016/j. breast.2017.02.001

10. Nagar H, Mittendorf EA, Strom EA, et al. Local-regional recurrence with and without radiation therapy after neoadjuvant chemotherapy and mastectomy for clinically staged T3N0 breast cancer. Int J Radiat Oncol Biol Phys. 2011;81(3):782-787. doi:10.1016/j. ijrobp.2010.06.027

11. Floyd SR, Buchholz TA, Haffty BG, et al. Low local recurrence rate without postmastectomy radiation in node-negative breast cancer patients with tumors $5 \mathrm{~cm}$ and larger. Int J Radiat Oncol Biol Phys. 2006;66(2):358-364. doi:10.1016/j.ijrobp.2006.05.001

12. Taghian AG, Jeong JH, Mamounas EP, et al. Low locoregional recurrence rate among node-negative breast cancer patients with tumors $5 \mathrm{~cm}$ or larger treated by mastectomy, with or without adjuvant systemic therapy and without radiotherapy: results from five national surgical adjuvant breast and bowel project randomized clinical trials. J Clin Oncol. 2006;24(24):3927-3932. doi:10.1200/ JCO.2006.06.9054
13. Jagsi R, Raad RA, Goldberg S, et al. Locoregional recurrence rates and prognostic factors for failure in node-negative patients treated with mastectomy: implications for postmastectomy radiation. Int J Radiat Oncol Biol Phys. 2005;62(4):1035-1039. doi:10.1016/j. ijrobp.2004.12.014

14. Frandsen J, Cannon G, Kokeny KE, et al. Post-mastectomy radiotherapy for pT3N0 breast cancers: a retrospective, multi-institution review. Breast J. 2017;23(4):452-455. doi:10.1111/tbj.12765

15. Goulart J, Truong P, Woods R, Speers CH, Kennecke H, Nichol A. Outcomes of node-negative breast cancer 5 centimeters and larger treated with and without postmastectomy radiotherapy. Int J Radiat Oncol Biol Phys. 2011;80(3):758-764. doi:10.1016/j. ijrobp.2010.02.014

16. Cassidy RJ, Liu Y, Kahn ST, et al. The role of postmastectomy radiotherapy in women with pathologic T3N0M0 breast cancer. Cancer. 2017;123(15):2829-2839. doi:10.1002/cncr.30675

17. Floyd SR, Taghian AG. Post-mastectomy radiation in large node-negative breast tumors: does size really matter? Radiother Oncol. 2009;91(1):33-37. doi:10.1016/j.radonc.2008.09.015

\section{Publish your work in this journal}

Cancer Management and Research is an international, peer-reviewed open access journal focusing on cancer research and the optimal use of preventative and integrated treatment interventions to achieve improved outcomes, enhanced survival and quality of life for the cancer patient.
The manuscript management system is completely online and includes a very quick and fair peer-review system, which is all easy to use. Visit http://www.dovepress.com/testimonials.php to read real quotes from published authors. 